\title{
Effect of Erythropoietin Administration on Spermatogonium Amount, Sertoli Cell and Leydig on Rats Testis (Wistar Strain) After Vas Deferens Ligation Released
}

\author{
Muhammad Surya Negara ${ }^{1}$, Soetojo ${ }^{1}$, Doddy M. Soebadi ${ }^{1}$ \\ ${ }^{1}$ Department Urology, Faculty of Medicine, Airlangga University, Surabaya 60115 Indonesia
}

\begin{abstract}
The study aimed to determine the effect of Erythropoietin on spermatogonia number, Sertoli cells and Leydig cells in white rat Wistar strain testis after ligation vas deferens release. Twenty-four Wistar strain eats were grouped into four group. The control group only performed an orchiectomy for testicular examination, ligation group vas deferens, group performed release ligation of vas deferens and group performed release ligation of vas deferens and given EPO injection with dose of $1000 \mathrm{iu} / \mathrm{kg} \mathrm{BW}$ intraperitoneally for a week (three times per week). The observation of spermatogonium, Sertoli cells and Leydig cells by determined amount on 5 cross sections of seminiferous tubules used 400x light magnificent microscope with Hematoxylin Eosin staining. The result showed ligation of vas deferens had significant decreased spermatogonia number and Sertoli cells $(\mathrm{p}<0.05)$. There was no significant difference Leydig cells number after ligation of vas deferens $(p>0.05)$. Meanwhile, release ligation of vas deferens had no significant different in spermatogonia, Sertoli cells and Leydig cells with ligation of vas deferens group. Besides, treatment ligation of vas deferens release and an EPO injection for a week also no significant different in number compared ligation release group of vas deferens.
\end{abstract}

Keywords: Vasectomy Reversal, Reactive Oxygen Species (ROS), Erythropoietin, Spermatogonium, Sertoli Cell, Leydig cell

\section{Introduction}

Vasectomy is most reliable form of male contraception and estimated 40 million to 60 million men worldwide had undergone vasectomy. Even though, vasectomy is very effective method but various problem can arise related to unclear patient information before action, surgical procedures, post-operative follow up and success rate ${ }^{1}$. Most common long term complications of vasectomy are scrotal pain with $1 \%$ reporting postoperative pain and spontaneous recanalization of vas deferens which occurred between $0.03 \%$ and $1.2 \%$ after vasectomy procedure was performed.

There were $2 \%$ men who had vasectomy choose to have vasectomy reversal because their desire to have children. The vasectomy reversal request are increased

\section{Corresponding author: \\ Soetojo}

E-mail: soetojo@fk.unair.ac.id in men who undergo vasectomy at young age ${ }^{1,2}$. Most men had vasectomy reversal will faced reducing in their semen quality and require additional reproductive techniques to achieve conception. The success rate in vasectomy reversal patients is around $90 \%$. Longer interval from patient undergoing vasectomy to reversal vasectomy, success rate for pregnancy is also getting lower ${ }^{3}$.

There are many hypotheses mentioned that vasectomy will result in obstruction of vas deferens which increasing intratesticular pressure in testis and resulted decreasing in testicular blood pressure and increased oxidative stress in the testis ${ }^{4,5,6}$. Vasectomy will result in high hydrostatic pressure due to obstruction, excessive sperm accumulation and stimulate local inflammatory reaction process which is characterized by increment in leukocytes in sperm. The abnormalities of sperm in the seminiferous tubules which contribute to Reactive Oxygen Species (ROS) increment? ${ }^{7}$. 
In contrast, vasectomy reversal will result in ROS increment which is greater than patients who do not have a vasectomy or those who have vasectomy ${ }^{8}$. When vasectomy reversal, long standing chronic inflammatory process activates even greater leukocyte activity in the vas deferens. Besides, pre existing immune mechanism which is formation of anti-sperm antibodies which stimulate another inflammatory reaction resulted in increment leukocyte activation. Reactive Oxygen Species (ROS) content in vasectomy reversal action is higher than for patients who have vasectomy resulting in disturbances in sperm motility and spermatogenesis ${ }^{8,9}$.

There was decreased in Sertoli cells, spermatogonia and spermatids and increased in apoptosis in spermatogenesis process ${ }^{10}$. Lue et al. indicated that testicles weight and testosterone hormone had no significant changes but spermatogonia number and Sertoli cells decrease significant after $6^{\text {th }}$ weeks and 울 tubular atrophy occurred at $12^{\text {th }}$ weeks ${ }^{11}$.

Erythropoietin(EPO) is most important growth factor produced in kidney and works on Erythroid progenitor cells in bone marrow to prevent programmed cell death and response to hypoxic conditions ${ }^{12}$. In additions, Erythropoietin receptors in the body also found in the brain, liver, digestive system, lungs, testiscles and Leydig cells. EPO can affect steroidogenesis of mouse testicular Leydig cells by stimulating testosterone production and EPO intravenously can increase testosterone production in renal failure ${ }^{12}$.

Besides, Erythropoietin has function as antiapoptosis, anti-inflammatory and antioxidant by inhibiting ROS. The EPO given to mice testes had improved morphological testicular structure and repair germ cells by reducing apoptosis process and preventing inflammatory process so that ROS process could be inhibited ${ }^{12,13}$. EPO have benefits by increasing spermatogonia number, Sertoli cells and Leydig cells. Hence, EPO is expected to be alternative therapy for vasectomy reversal. .The study aimed to determine the effect of Erythropoietin on spermatogonia number, Sertoli cells and Leydig cells in white rat Wistar strain testis after ligation vas deferens release.

\section{Methodology}

The study was used experimental study with post test only control group design used male Wistar white rats (Rattus norvegicus). In additions, the treatment was in form of vasectomy ( ligation of vas deferens) which observed for seven weeks, release ligation and left for one week and EPO injection for one week (3 times per week). The effect on spermatogonia number, Sertoli cells and Leydig cells in the testes was observed after ligation of vas deferens.

In the study, a post-test only control group design study was used with assumption that variable measurement were only obtained after treatment and had criteria for random allocation. The sample used was Wistar strain of white rats (Rattus Norvegicus) which had criteria included aged between 10 weeks and 12 weeks, body weight between 150 gram and 200 grams, healthy and not disabled. The white rats was obtained from breeding laboratory at Faculty of Veterinary Medicine, Airlangga University.

The samples were divided into four groups randomly with random numbers. Overall samples were 36 Wistar strain (Rattus norvegicus). The treatment consisted 3 groups included one group treated with a vasectomy and observed for 7 weeks; one group with vasectomy and release ligation performed at $7^{\text {th }}$ weeks and then observed for another one week and another group with vasectomy treatment and release ligation was carried out at $7^{\text {th }}$ weeks and given EPO injection was give for one week (3 times per weeks).

The study was conducted at Reproductive Embryology section of Faculty of Veterinary Medicine, Airlangga University for experimental animal rearing places and Pathobiology section of Anatomical Pathology section of Faculty of Veterinary Medicine for anatomical pathology examination and immunohistochemistry of testicular tissue examined.

The independent variable was EPO administration in Wistar strain rats after release ligation of vas deferens. Meanwhile, dependent variables was spermatogonia number, Sertoli cells and Leydig cells and control variables included Wistar strain (Rattus norvegicus), rats age, weight, cage type, feed, temperature, air pressure, cage humidity, artificial reversal vasectomy by release ligation of vas deferens, vasectomy duration and EPO dose.

The normality and variance test were used as basis for determined hypothesis test to determine the differences in spermatogonia number, Sertoli cells and Leydig cells in the control group and treatment group. All 
data process techniques were analyzed computerizable used SPSS software program.

\section{Result and Discussion}

The data was analyzed used One Way ANOVA test. The result showed there were significant differences in Sertoli cells in each group with $\mathrm{p}<0.05$. The analysis continued with Post Hoc test to determine differences in each group. There was significant difference in Sertoli cells number in the control group compared to group who received vasectomy $(\mathrm{p}<0.05)$, where Sertoli cells number in the control group was higher than in vasectomy group. In this study, the vasectomy had reduced Sertoli cells significantly. Besides, group with release ligation and group with release ligation and EPO found did not significantly affected Sertoli cells number $(\mathrm{p}>0.05)$. In additions, group with release ligation and group with release ligation and EPO found that there was no significant difference compared group with only vasectomy. The group with release ligation of vas deferens was observed had lower Sertoli cell than group with vasectomy which is released by ligation.

Table 1. Comparison of Post Hoc Tamhane analysis for Sertoli cells in ach group.

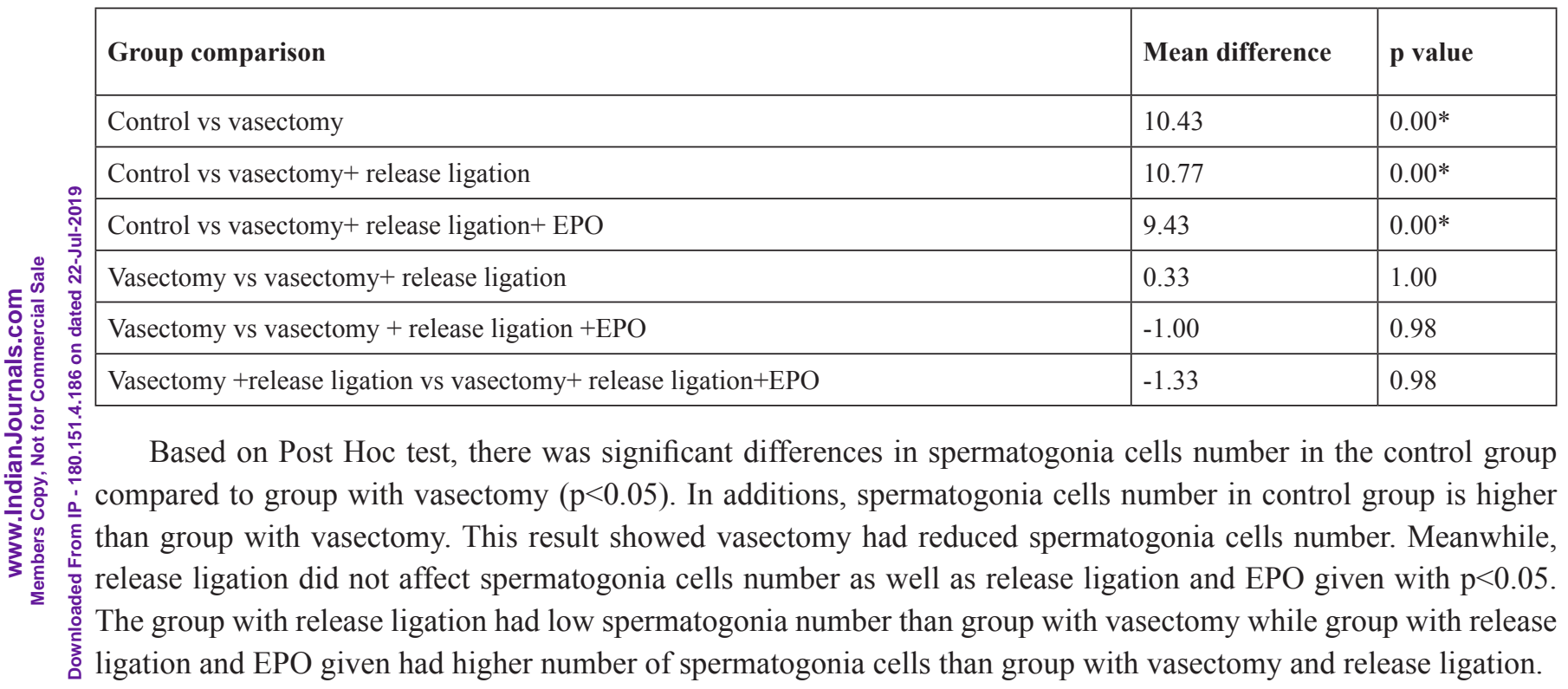

Table 2. Comparison of Post Hoc Tamhane analysis on spermatogonia cells number in each group

\begin{tabular}{|l|l|l|}
\hline Group comparison & Mean difference & p value \\
Control vs vasectomy & 15.97 & $0.00 *$ \\
Control vs vasectomy+ release ligation & 16.80 & $0.09 *$ \\
Control vs vasectomy+ release ligation+ EPO & 9.90 & $0.08 *$ \\
Vasectomy vs vasectomy+ release ligation & 0.83 & 1.00 \\
Vasectomy vs vasectomy + release ligation +EPO & -6.06 & 0.42 \\
Vasectomy +release ligation vs vasectomy+ release ligation+EPO & -6.90 & 0.82 \\
\hline
\end{tabular}

The visualization of microscopic description of cross section of seminiferous tubule in control group is shown in Figure 1.The visualization of microscopic view of cross section of seminiferous tubulegroup rats is shown in Figure 2. As for vasectomy group and release for one week, its visualization is shown in Figure 3. Finally, for vasectomy group + release of vas deferens + one week IPO, its microscopic images is shown in Figure 4. 


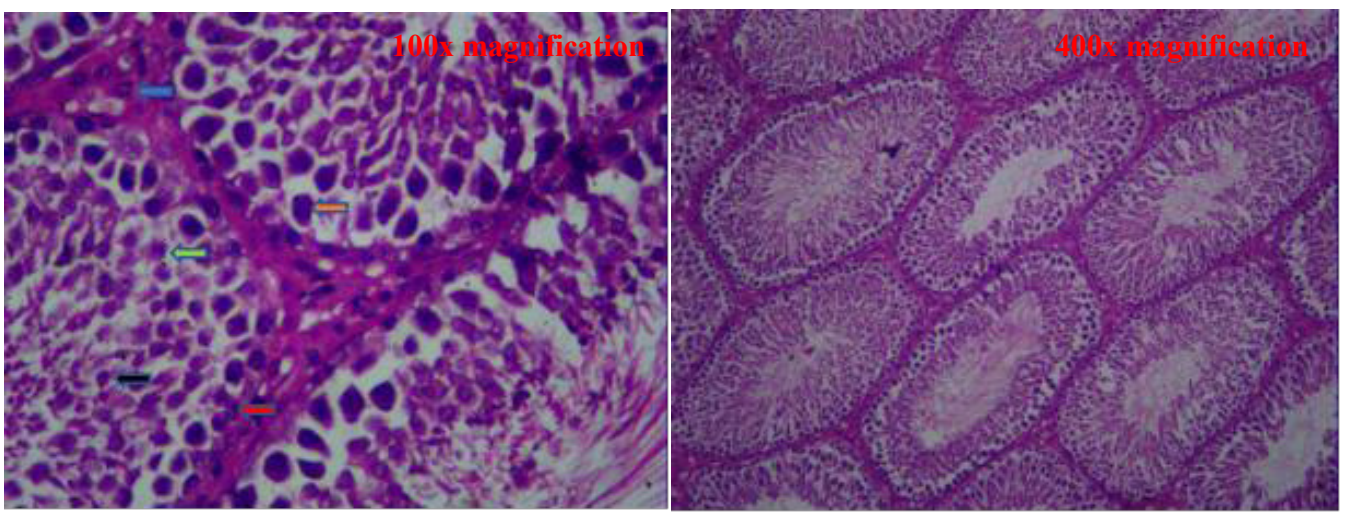

Figure 1. Microscopic description of cross section of seminiferous tubule in control group. Description: Blue arrow sowed Leydig cell. Green arrows indicated spermatocyte cells. The orange arrow showed spermatogonia cells. Red arrow indicated Sertoli cells. Black arrows showed spermatid cells

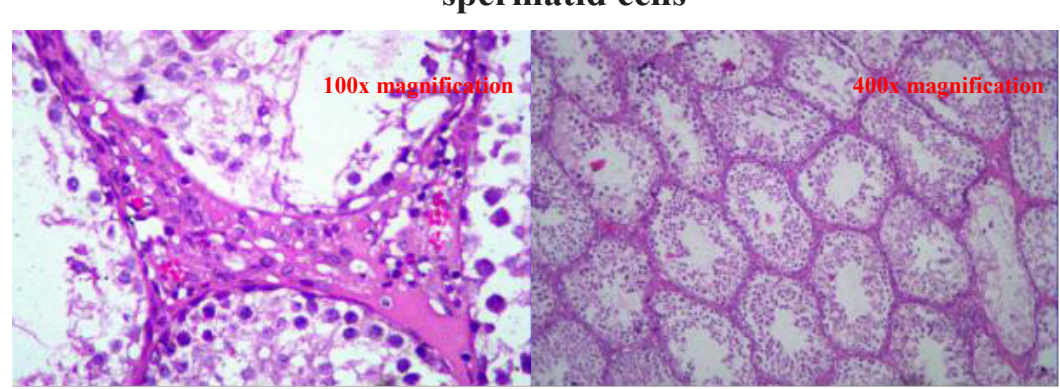

Figure 2. Microscopic view of cross section of seminiferous tubule in 7 weeks vasectomy group rats.

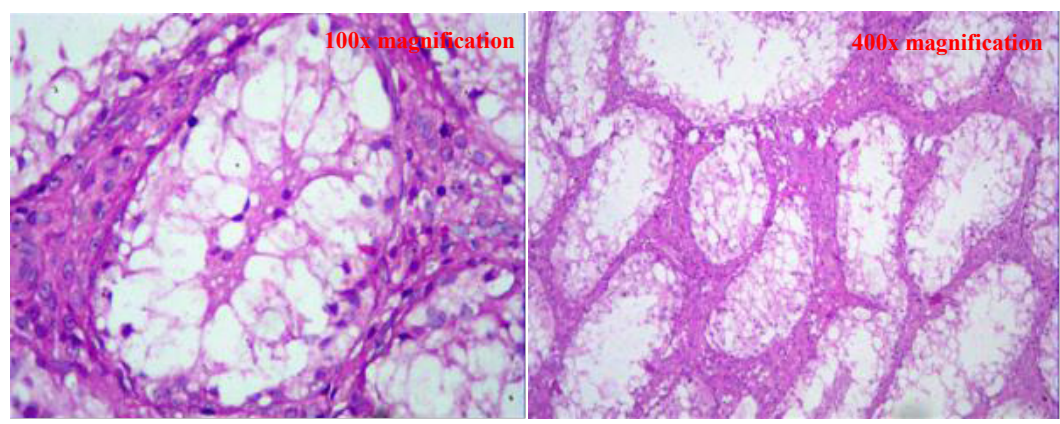

Figure 3. Microscopic view of cross section of seminiferous tubules in 7 weeks vasectomy group and release for one week

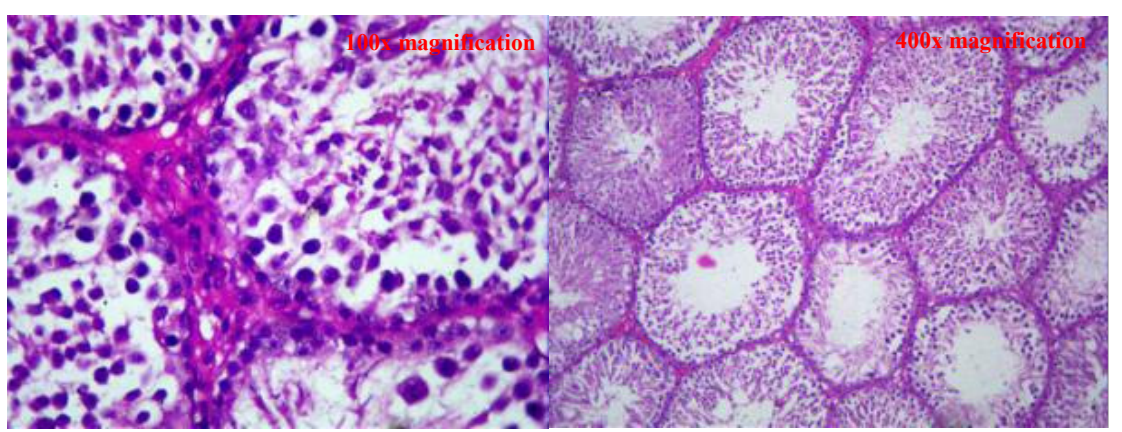

Figure 4. Microscopic description of cross section of seminiferous tubules in 7 weeks vasectomy group + release of vas deferens + one week IPO 


\section{Discussion}

A reversal vasectomy was an act of returning vasectomy by reconnected vas deferens either by vasovasostomy or vasoepididymostomy. The reversal vasectomy is usually performed in $2-6 \%$ men who had a vasectomy before. The success rates for reversal vasectomy were determined by several factors included duration between vasectomy and reversal vasectomy, operator skills and intra-operative and pre-operative factors ${ }^{1}$. The patency rate and success of pregnancy after reversal vasectomy was around $97 \%$ and $76 \%$. Meanwhile, between 3 years and 8 years intervals the patency and success rates were around $88 \%$ and 53\%.

Vasectomy was resulted in high hydrostatic pressure due to the obstruction, excessive sperm accumulation and stimulated local inflammatory reaction process which characterized by an increment in leukocytes in the sperm and abnormality of sperm in seminiferous tubules that played a role in increased Reactive Oxygen Species (ROS).

The inflammatory process had increased leukocytes and secrete pro-inflammatory cytokines such as TNF- $\alpha$, IL-6, IL-8, NF- $\kappa$ B and TGF- $\beta$ that increased ROS and iNOS(Inducible Nitric Oxygen) activity species ${ }^{14}$. In the testis, the cells expressed TNF- $\alpha$ receptors, IL- 6 were sensitive to hypoxic conditions were spermatogonia. The leukocytes and IL-6 concentration in seminiferous tubules remained stable during release ligation of vas deferens treatment due chronic inflammatory process of vasectomy.

In this study, vasectomy significantly reduced spermatogonia and Sertoli compared to control group $(p<0.05)$ because vasectomy in vas deferens tract was blocked so that obstruction occurred and there was an increase in intratesticular pressure in the testis. The inflammatory process had increased leukocytes and secrete proinflammatory cytokines such as TNF- $\alpha$, IL-6 which mediator had bind to TNF- $\alpha$ receptors (TNF- $\alpha \mathrm{R}$ ) and IL-6-R found in spermatogonia.

Chronic inflammatory reactions due to vasectomy obstruction caused an increment in macrophages resulted in leucocyte infiltration into the plasma seminal ${ }^{15}$. The apoptosis activation process also increased ROS and NOS resulted in degeneration of the seminiferous tubules, the blood testicular barrier was damaged and spermatogonia number and Sertoli cells also decreased.
Meanwhile, there was no significant difference in Leydig cells after vasectomy with control group $(\mathrm{p}>0.05)$. Naik et al. had stated vasectomy did not affect significantly in the FSH hormones, LH and testosterone while Leydig cells plays a role in producing testosterone ${ }^{16,17}$. Leydig cells were interstitial compartment of testes along with macrophages and lymphocytes which were located in Leydig cells between seminiferous tubules.

In this study, the reversal vasectomy was analogized to release of vasectomy ligation since vasectomy had performed also an artificial vasectomy by double ligation of vas deferens of mouse testes for 7 weeks with nonabsorbable threads and no any cutting either proximal to ligation of vas deferens or distal from ligation of vas deferens.

In group with vasectomy for 7 weeks and release ligation with left for one week, there was no statistically significant difference from spermatogonia number, Sertoli cells and Leydig cells with group with vasectomy for 7 weeks $(p>0.05)$. The spermatogonia number, Sertoli cells and Leydig cells after release ligation of vas deferens had lower number than group with vasectomy. In reversal vasectomy, leukocytes and IL-6 in seminal plasma was remain stable due to chronic inflammatory vasectomy process and increased which affected ROS activities.

Furthermore, group with EPO injection after release ligation of vas deferens showed no significant difference in spermatogonia, Sertoli cells and Leydig cells compared to group with vasectomy. The number of spermatogonia cells, Sertoli cells and Leydig cells were observed increased on group with EPO injection after one week observation. EPO had function as an antiinflammatory, anti-apoptotic and antioxidant which also known that there were EPO receptors in the testes.

\section{Conclusion}

In conclusions, Sertoli cells and spermatogonia number less than the control group. Meanwhile, Leydig cells number in vasectomy group was higher than control group. Sertoli cells, Leydig cells and spermatogonia in vasectomy and release ligation of vas deferens was higher compared group with vasectomy. Besides, Sertoli cells, Leydig cells and spermatogonia in vasectomy group and release ligation of vas deferens with EPO for one week also higher than group with vasectomy and release ligation of vas deferens. The administration 
of EPO for one week did not affected spermatogonia, Sertoli cells and Leydig cells numbers in release ligation of vas deferens treatment.

Ethical Clearance: Taken from the committee

Source of Funding: Nil

Conflict of Interest: Nil

\section{References}

1. G.R. Dohle, T. Diemer, Z. Kopa, C. Krausz, A. Giwercman, A. Jungwirth. "European association of urology guidelines on vasectomy". European Urology. 2012;61(1):159-163.

2. A. Zini, J. Grantmyre, P. Chan. "CUA guideline: vasectomy". Canadian Urological Association. 2016;10(7-8):E274-E278.

3. R. G. Mason, P. G. Connell, J.C. Bull. "Reversal of vasectomy using a macroscopic technique: a retrospective study". Annals of the Royal College of Surgeons of England.1997;79(6):420-422.

4. J. Liu, C. T. Rong, Y. Li, X.X. Liu, W.T. Wang, N. Li. "Vasectomy induces oxidative stress and up-regulates the expression of peroxiredoxins in mouse testis in short and early periods after surgery". Journal of Urology. 2014;191(6):19201926.

5. A. Faramarzi, B. Seifi, H.R. Sadeghipour, A. Shabanzadeh, M. Ebrahimpoor, "Prooxidantantioxidant balance and malondialdehyde over time in adult rats after tubal sterilization and vasectomy,"Clinical and Experimental Reproductive Medicine. 2012;39(2):81-86.

6. F.I. Duru, S. Ajayi, O.O. Azu. "The effect of unilateral vasectomy on testosterone and testicular parameters in the adult African giant rat (Cricetomysgambianus)". African Health Sciences. 2013;13(2):483-489.

7. A.M. Bernie, E. C.Osterberg, P. J. Stahl, R.Ramasamy, M. Goldstein. "Vasectomy reversal in humans". Spermatogenesis. 2012;2(4):273278.

8. R.H. Shapiro, C.H. Muller, G. Chen, R.E. Berger. "Vasectomy reversal associated with increased reactive oxygen species production by seminal fluid leukocytes and sperm,"Journal of Urology. 1998;160(4):1341-1346.

9. P. N. Kolettis, R.K. Sharma, F.F. Pasqualotto, D. Nelson, A.J. Jr. Thomas, A. Agarwal. "Effect of seminal oxidative stress on fertility after vasectomy reversal". Fertility and Sterility. 1999;71(2):249-255,.

10. S. Alpcan, H. Basarm T.R. Aydos, O. Kul, Ü. Kisa, M.M. Basar. "Apoptosis in testicular tissue of rats after vasectomy: evaluation of eNOS,iNOS immunoreactivities and the effects of ozone therapy". Turkish Journal of Urology. 2014;40(4):199-206.

11. Y. Lue, A.P. Hikim, C. Wang, J.J. Bonavera, S. Baravarian, A. Leung and R.S. Swerdloff, "Early effects of vasectomy on testicular structure and on germ cell and macrophage apoptosis in the hamster,'Journal of Andrology. 1997;18(2):166173.

12. N. Yazihan, H. Ataoglu, N. Koku, E. Erdemli, A.K. Sargin. "Protective role of Erythropoietin during testicular torsion of the rats,"World Journal of Urology. 2007;25(5):531-536.

13. F. K. Rashed, B. Ghasemi, H. D. Mogaddam, M. Mesgari. "The effect of Erythropoietin on ischemia/reperfusion injury after testicular torsion/detorsion: a randomized experimental study". ISRN Urology. 2013.

14. Y, Zhang et al. "Erythropoietin action in stress response, tissue maintenance and metabolism". International Journal of Molecular Sciences. 2014;15(6):10296-10333.

15. C.J. Flickinger, J.C. Herr, D. Caloras, J.R. Sisak, S.S. Howards. "Inflammatory changes in the epididymis after vasectomy in the Lewis rat,"Biology of Reproduction. 1990;43(1):34-45.

16. C.M. McVicar, D.A. O’Neill, N. McClure, B. Clement, S. McCullough, S.E. Lewis. "Effects of vasectomy on spermatogenesis and fertility outcome after testicular sperm extraction combined with ICSI,"Human Reproduction. 2005;20(10):2795-2800. 